\title{
Rainfall Forecasting Using Various Artificial Neural Network Techniques - A Review
}

\author{
Nisha Thakur*, Sanjeev Karmakar, Sunita Soni \\ Computer Science and Engineering, Chhattisgarh Swami Vivekanand Technical university,Bhilai Institute of \\ Technology, Chhattisgarh, India
}

\begin{abstract}
Article Info

Volume 7, Issue 3

Page Number: 403-409

Publication Issue :

May-June-2021

\section{Article History}

Accepted : 12 June 2021

Published : 22 June 2021

The present review reports the work done by the various authors towards rainfall forecasting using the different techniques within Artificial Neural Network concepts. Back-Propagation, Auto-Regressive Moving Average (ARIMA), ANN , K- Nearest Neighbourhood (K-NN), Hybrid model (WaveletANN), Hybrid Wavelet-NARX model, Rainfall-runoff models, (Two-stage optimization technique), Adaptive Basis Function Neural Network (ABFNN), Multilayer perceptron, etc., algorithms/technologies were reviewed. A tabular representation was used to compare the above-mentioned technologies for rainfall predictions. In most of the articles, training and testing, accuracy was found more than $95 \%$. The rainfall prediction done using the ANN techniques was found much superior to the other techniques like Numerical Weather Prediction (NWP) and Statistical Method because of the non-linear and complex physical conditions affecting the occurrence of rainfall.

Keywords : Artificial Neural Network (ANN), Backpropagation algorithm, ANN Architecture, Auto-Regressive Moving Average (ARIMA), Adaptive Basis Function Neural Network (ABFNN).
\end{abstract}

\section{INTRODUCTION}

Rainfall has an important role to play as far as Asian countries are concerned. India is one of those countries which directly or indirectly driven by the rainfall. Most of the people residing in villages are dependent on agriculture, and fruitful agriculture depends on the Rain, in most of the parts of India. Therefore balanced rain is needed for proper agriculture results. Rainfall prediction becomes even more important, in case of possibilities of deficient or excess rain. When there is a possibility of excess rain, the people may suffer from flooding. Hence to prevent, these flooding situations, to manage resources, and most importantly to save the human life rainfall prediction is so important. The deficient rainfall has also an adverse effect on humans or animals because it may affect the water quality and

Copyright: () the author(s), publisher and licensee Technoscience Academy. This is an open-access article distributed under the terms of the Creative Commons Attribution Non-Commercial License, which permits unrestricted non-commercial use, distribution, and reproduction in any medium, provided the original work is properly cited 
aquatic ecosystem. Rainfall prediction can help in controlling the adverse situation created due to the excess or deficient rain.

An accurate forecasting is a difficult assignment in the field of rainfall prediction. There are various methods of rainfall prediction or forecasting like Statistical Method, Numerical Weather Prediction (NWP), and Machine Learning Methods but the Artificial Neural Network (ANN) which belongs to Machine Learning techniques is more suitable so far as rainfall predictions are concerned because the physical conditions affecting the occurrence of rainfall are non-linear and highly mosaic (Nayak et al. 2013, Adamowski et al. 2010).

Rainfall time series forecasting models play a vital role in many real-world applications such as drinking water supply (Sahai et al., 2000; Singh and Borah, 2013) ,reservoir's operation and flooding prevention (Luk et al., 2001; Wu et al., 2010), rain-fed agricultural activities, water resources planning and management (Kajornrit et al., 2013), hydroelectric power generation, and facilities maintenance and control such as airport management (Benedetto, 2002). The task of rainfall prediction involves a large degree of uncertainty as rainfall is one of the most complex and difficult elements of the hydrology cycle to understand and model (French et al., 1992). Due to the complexity of the atmospheric processes that generate rainfall and the lack of available data on the temporal and spatial scales, it is not feasible generally to forecast rainfall using a statistical or physically based process model (Luk et al., 2001). While physically based models are very useful to understand the physical mechanisms involved in the hydrological process, they are difficult to apply as they require a large number of parameters to model the complexity of the process. It is also very difficult to extend a particular model to even slightly different conditions and situations. Statistical models too are not suitable to analyse the nonlinear relationships between rainfall and parameters that cause rainfall
(Guhathakurta, 2006). The accuracy of rainfall time series forecasting is fundamental to many decisionmaking processes and hence there is a need for improving the effectiveness of forecasting models.

\section{LITERATURE SURVEY}

Sahai et al. (2000) has choosen the task for predicting the ISMR as they believed that prior knowledge of monsoon behavior may very crucially in the countries like India, where the amount of rainfall in the monsoon season is an important factor in making policies and agricultural practices. They explored the application of ANN as a forecasting tool as they believed that the traditional sophisticated empirical statistical models and the dynamical prediction models particularly General Circulation Models (GCMs) have limited success in predicting ISMR. Backpropagation ANN was applied by them to predict the average summer monsoon rainfall amount in India on monthly and seasonal time scales. Two hidden layers architecture (25-2-4-1) and two different activation functions for the hidden layer were used in this study. Their results exhibited reasonably good resemblance with the test data.

Toth et al. (2000) compared short-term rainfall prediction models for real-time flood forecasting. They applied three-time series models, autoregressive moving average (ARMA), ANN and knearest-neighbors (KNN) method for forecasting storm rainfall occurring in the Sieve River basin, Italy, in the period 1992- 1996 with lead times varying from 1 to $6 \mathrm{~h}$. The result expressed that the ANN exhibited the best in the improvement of the runoff forecasting accuracy when the predicted rainfall was used as inputs of the rainfall run-off model.

Maeda et al. (2001) examined precipitation using mean square error and the Critical Success Index (CSI) methods. The practical results of the two assessments expressed that in the CSI evaluation; the neural network approach can efficiently predict for the 
coming hour and may be used as a practical tool for reducing snow hazards.

Luk et al. (2001) discussed three types of ANNs for rainfall forecasting. Multi-Layer Feed Forward Neural Network (MLFN), Elman partial recurrent neural network and Time-Delay Neural Network (TDNN) performance were compared regarding error rate. The experimental results reported the above systems may perhaps make an acceptable rainfall forecast. Consequently, the number of hidden nodes incurred the optimal complexity and time delay of the network. The proposed neural network architectures had comparable performance and trained to reach their optimal complexities when they were developed.

Solomatine (2003) gave a divide and conquer approach where the complete region is divided into four sub-areas and each is modelled with a different method. For two larger areas, they have used radial basis function (RBF) networks to perform rainfall prediction. The other two smaller sub-areas, they have used a simple linear regression model to predict the rainfall. Both techniques have almost similar performance for 1-h ahead prediction of runoff, but the result of the ANN is slightly better than the Model Tree for higher lead times.

Philip and Joseph (2003) observed that even though rainfall is unpredictable, it exhibits certain periodicity when monitored over a long period. ANNs were used to understand the periodicity in the rainfall pattern. Therefore, they collected a data set containing monthly rainfall data recorded at Trivandram, Kerala for the period 1893 to 1933.

Srikalra and Tanprasert (2006) reported a study on daily rainfall prediction with neural networks using rainfall data set of each rain gauge station around Chao Phraya River (Thailand) for a period from 2002 to2005. Backpropagation neural network was used for training and testing the forecast model. The average accuracy of the training set and testing set was reported as $97.42 \%$ and $95.44 \%$ respectively. The results expressed, the possibilities of predicting the rainfall using ANN on daily basis with significant accuracy. They also recommend the use of additional inputs like temperature and humidity for better performance of the models.

Kumar et al. (2007) reported the use of Backpropagation ANNs with Steepest gradient techniques for predicting the seasonal and monthly rainfall and performance of seasonal rainfall models were reported to be better on comparision with the monthly prediction models.

P. Guhathakurta (2008) reported a deterministic neural network model for monthly rainfall time series data Using the back-propagation learning algorithm. The performances of this model were encouraging.

Nasseri et al. (2008) employed an ANN model with Backpropagation algorithm integrated with the Genetic algorithm to predict rainfall in Australia. The author observes MLP type network coupled with GA, consistently performed better than MLP network alone. Mar and Naing (2008) presented ANN to forecast the total monthly rainfall in Yangon, Myanmar. This investigation was carried out for the period 1970 - 2006 as input. They reported that the performance of the neural network model is satisfactory, and feasible for rainfall forecast model in Myanmar regions.

Hung et al. (2009) reported an ANN technique for improving rainfall forecast performance in Bangkok located in Thailand using four years of hourly data collected from 75 rain gauge stations. It was applied to the real-time rainfall forecasting and flood management. They reported a generalized feedforward ANN model using hyperbolic tangent transfer function and the use of a suitable combination of meteorological parameters permitted the model to solve forecasting issues at any instant of time.

Dahamsheh and Aksoy (2009) used FFBPN and Multiple Linear Regression (MLR) methods for 
forecasting monthly rainfall for four meteorological stations from various regions in Jordan. They concluded that ANNs are slightly better than the MLR in predicting the total monthly precipitation.

Precise precipitation data are essential for the planning and management of water resources (Hung et al., 2009). Luk et al. (2001) wrote that the dynamism of rainfall in space and time, however, renders quantitative forecasting of rainfall tough. As rain prediction uses more complex and nonlinear data pattern; the need for more new forecasting approaches to improve the forecasting accuracy was heightened by Hong (2008).

Vamsidhar et al. (2010) proposed a backpropagation neural network model for predicting the rainfall based on humidity, dew point and pressure in India. The experimental results for proposed models gave 99.79\% accuracy in training and $94.28 \%$ accuracy in testing. The rainfall data has been taken of 100 years. Two-third of the data is used for training and onethird is used for testing.

Avik G. D., et al., (2010) reported a Backpropagation neural network with architecture 3:7:1, for forecasting the rainfall based on humidity, dew point and pressure They used two-third of the data for training and one-third for testing. The results obtained expressed $99.79 \%$ of accuracy in training and $94.28 \%$ of accuracy in testing.

El-Shafie et al. (2011) used ANN and MLR rainfall prediction models for forecasting rain in Alexandria, Egypt on the yearly and monthly data. They reported that the FFNN model performance and the acquired result are better than acquired using the MLR model. They also reported that the linear nature of the MLR model estimators made it inadequate in giving good prognostics for a variable characterized by a highly nonlinear physics. It was observed that the ANN model is a nonlinear mapping tool, which is better for rain (nonlinear science) prediction as compared to other techniques.
Khalili et al. (2011) also used ANN used daily rainfall data of March, May and December months with (high and medium humidity) for a duration from 1986 to 2010 for modelling daily rainfall forecasting in the Mashhad synoptic station. They reported that it is feasible to employ the prior information in everyday rainfall modelling to implement a grey box ANN model in place of black box ANN to improve the prediction performance.

Moustris et al. (2011) worked on ANNs to predict the month-wise maximum rainfall, minimum precipitation, average and total cumulative precipitation during a period of the next four consecutive months. For this rainfall data of the 115 years (1891-2005) were used. The results expressed that the ability of ANNs as a precipitation forecasting tool looked to be entirely satisfactory. They also concluded that the ANNs could be used in forecasting the seasonal and monthly precipitation.

Olaiya and Adeyemo (2012) implemented ANN models and decision tree algorithm (DTA) to predict maximum temperature, rainfall, evaporation and the speed of the wind at Ibadan city, Nigeria. In their investigation, the performance of the Time-Lagged Feed Forward Network (TLFFN) and recurrent networks and DT algorithms were studied using the meteorological data collected for a period of nine years i.e. from 2000 to 2009 from the city of Ibadan located in Nigeria. The results concluded that ANN as a suitable tool for meteorological predictions.

Mandal and Jothiprakash (2012) used two models of ANN and Model Tree (MT) to forecast next time step rainfall using 47 years of daily rainfall records at Koyna Dam, Maharashtra, India. The authors reported that both the models, ANN and MT as reliable rainfall forecast model.

Nayak et al. (2013) examined various ANN models for forecasting rainfall. In addition to BPN and RBFN, they also deliberated on the use of Support Vector Machines (SVM) and Self- Organising Maps (SOM) as 
an alternative rainfall prediction tool for the traditionally used numerical and statistical models.

$\mathrm{Wu}$ and Chau (2013) used the data pre-processing and modular approach for predicting daily and monthly rainfall using soft computing techniques. They used the same dataset presented by $\mathrm{Wu}$ et al. (2010). They compared to the prediction performance of persistence and ANN models, though ANN-MA and ANNSSA exhibited better forecasting accuracy, MA technique was proven to be more accurate for daily and monthly rainfall predictions.

Venkata Ramana et al. (2013) gave a hybrid model combining wavelet techniques and ANN (WNN) for monthly rainfall forecasting in Darjeeling located in India. A comparison was done between ANN and WNN. They used monthly rainfall, minimum and maximum temperature data of the duration of 74 years starting from 1st January 1901 to 1st September 1975 from the rainfall at Darjeeling rain gauge station. Data from the initial 44 years (60\%) were used for the process of calibration and the remaining 26 years of data $(40 \%)$ were used for the process of validation. From this study, it was found that the efficiency index was greater than $94 \%$ for WNN models whereas it was $64 \%$ for ANN models.

Badaoui et al. (2013) expressed that ANNs especially MLP network as a suitable model for the forecasting of moisture in the area of Chefchaouen in Morocco. Their study showed that the predictive models established by the ANN method are more efficient in comparison to the established methods based on MLR. Bodri (2001) proposed an ANN model for rainfall forecasting. Back trainer propagation algorithm is used to train the network with 38 years of actual annual and monthly precipitation data from east Hungarian meteorological stations. The results have shown that comparatively any neural network model with an acceptable choice of the input data can achieve enhanced accuracy in predicting future precipitation values from existing actual data.
Chen et al. (2013) examined the Feed Forward Backpropagation Network (FFBPN) and Conventional Regression Analysis (CRA) for estimating rainfallrunoff. The authors reported FFBPN as a reliable tool for modelling hydrological predictions.

K.S. Kasiviswanathan (2013) reported that a twostage optimization procedure is envisaged in this study for the construction of the prediction interval for the ANN output. The study carried out suggested that the method results a fairly accurate estimate for uncertainty indices. Garcia et al. (2014) presented a comparative analysis of SVM, with decision trees, Knearest neighbour and several alternative neural computations based approaches such as multilayer perceptron, ELM for accurate prediction of daily precipitation.

Alhashimi (2014) presented three various rainfall prediction models that were developed based on ARIMA, ANN and MLR. Monthly rainfall estimation was done. Monthly rainfall measurements, average temperature, wind speed and relative humidity collected from Kirkuk station for a period from 1970 to 2008 were the input predictors that were applied to train and test the forecast models. They reported the multi-layer feed-forward Backpropagation neural network model forecast to be better than the other two models.

Solgi et al. (2014) have proposed a hybrid model (Wavelet-ANN) for short and long daily precipitation forecast. The prediction result of wavelet-ANN model is compared with an adaptive neuro-fuzzy model and it is observed that wavelet-ANN model gives a satisfactory result.

Farajzadeh et al. (2014) applied FFNN and ARIMA models to predict the monthly rainfall in the Urmia lake basin. The authors reported the values estimated by monthly rainfall through Feed-forward NN were close to the ARIMA model.

Devi et al. (2015) worked on various neural network models such as feed-forward Backpropagation neural network (BPN), cascade-forward Backpropagation 
neural network (CBPN), distributed time-delay neural network (DTDNN) and nonlinear autoregressive exogenous network (NARX). Momentum learning, conjugate gradient descent (CGD) learning, and Levenberg Marquardt proved to be the best weight updating technique for all the network models.

A BPNN algorithm model for forecasting rainfall in Tenggarong, East Kalimantan - Indonesia was reported by Mislan (2015). After testing the three architectures with various values of epochs such as 500, 1000 and 1500, BPNN models were reported as a predictive algorithm that provides a good forecasting accuracy.

A model for weather forecasting using ANN (Artificial Neural Network) with Backpropagation algorithm and comparison of the results with General Regression Neural Network (GRNN), Ensemble Neural Network, Backpropagation Neural Network (BPNN), Radial Basis Function Network (RBFN), Genetic Algorithm (GA), Multi-Layer perceptron (MLP), and fuzzy clustering for rainfall prediction was reported by Narvekar and Fargose (2015).

Partal et al. (2015) developed and compared the performance of FFBN, wavelet transformation and RBFN for daily precipitation predictions. This study reported that wavelet FFBPN model was better for practical application in guiding the design of wavelet neural networks.

Nanda et al. (2016) used a hybrid Wavelet-NARX model for flood forecasting and warning system. They also compared different models like WaveletNARX model, ARMA model, ANN model and Wavelet-ANN models. The authors reported that the Wavelet-NARX model performed better than all the other models.

Abdulkadir et al., (2017) implemented soft computing techniques comprising both ANN and Fuzzy Logic. The results were compared with Radial Basis Function. The authors also elaborated the advantage of allowing the analyst to understand and interact with the model using fuzzy rule base system.

Multi-Layer Perceptron (MLP) Network with two different algorithms were used by Hashim et al. (2017) for Rainfall prediction. The Multilayered perceptron trained with Lavenberg Marquardt algorithm produced better results with an accuracy percentage of $99.75 \%$ which was better as compared to the backpropagation algorithm which gave an accuracy of $94.75 \%$. Multilayer perceptron (MLP) model with a back-propagation algorithm was observed to be the best among the ANN models by Acharya et al. (2017). Their study also suggested that the MLP model with a backpropagation (BP) algorithm was the best amongst the other ANN models.

Rain Prediction by a multiple regression model was also done by Ping-Cheng Hsieh et al. (2019) and found accurate results. Table 01, illustrates the comparison between the work done by the various researchers in rainfall prediction using various ANN techniques. Cite this article as :

\section{III.RESULTS AND DISCUSSION}

The studies of rainfall/weather forecasting are being carried out all over the world. It is also observed that none of the models works for all the time and for all over the world. This is because the weather parameters are very sensitive. They keep changing over the period. Hence a careful study is essential to monitor the performance of these models.

A detailed survey on rainfall forecasting using various neural network techniques along with different types of architectures, over twenty-five years was done. Most of the researchers looked to be working on Backpropagationn neural network with Levenberg Marquardt algorithm for rainfall prediction because of fairly good results found 
using it, as compared to other neural network techniques for forecasting.

Forecasting techniques using various algorithms such as MLP (Multi-Layer Perceptron), BPN (Backpropagationn Network), ARIMA (Auto Regressive integrated moving average), MT (Model Tree), ANFIS (Artificial Neural Fuzzy Inference System), WNN (Wavelet Neural network) and SVR (Support Vector Regression) were reported suitable to predict rainfall. The errors and the RMSE values reported for prediction using neural network were significantly below when the same is considered for a few statistical and numerical methods.

TABLE I

TRAINING AND TESTING ACCURACY REPORTED BY VARIOUS AUTHORS

\begin{tabular}{|c|l|c|c|c|}
\hline$\cdot$ & \multicolumn{1}{|c|}{ Algorithm } & Author (s) & Training(\%) & Testing(\%) \\
\hline 1 & Error BPN & Basu and Andharia & 76.00 & 89.00 \\
\hline 2 & Regression Equation & Shukla and Mooley & 70.00 & 68.00 \\
\hline 3 & Hybrid Algorithm & Sahai et al. & 78.00 & 95.00 \\
\hline 4 & Backpropagation ANN (5:10:01) & Srikalra and Tanprasert & 97.42 & 95.44 \\
\hline 5 & Backpropagation ANN (3:7:1) & Vamsidhar et al. & 99.79 & 94.28 \\
\hline 6 & WNN Model:- & Venkata Ramana et al. & 98.48 & 94.78 \\
\hline 7 & ANN Model:- & Venkata Ramana et al. & 81.49 & 64.73 \\
\hline 8 & WANN Model:- & Solgi et al. & 74.20 & 52.50 \\
\hline 9 & ANFIS Model:- & Solgi et al. & 56.20 & 63.20 \\
\hline 10 & Backpropagation-9 Hidden nodes & Hashim et al. & 95.67 & 93.47 \\
\hline 11 & $\begin{array}{l}\text { Levenberg Marquardt - 3 Hidden } \\
\text { nodes }\end{array}$ & Hashim et al. & 99.90 & 99.60 \\
\hline
\end{tabular}




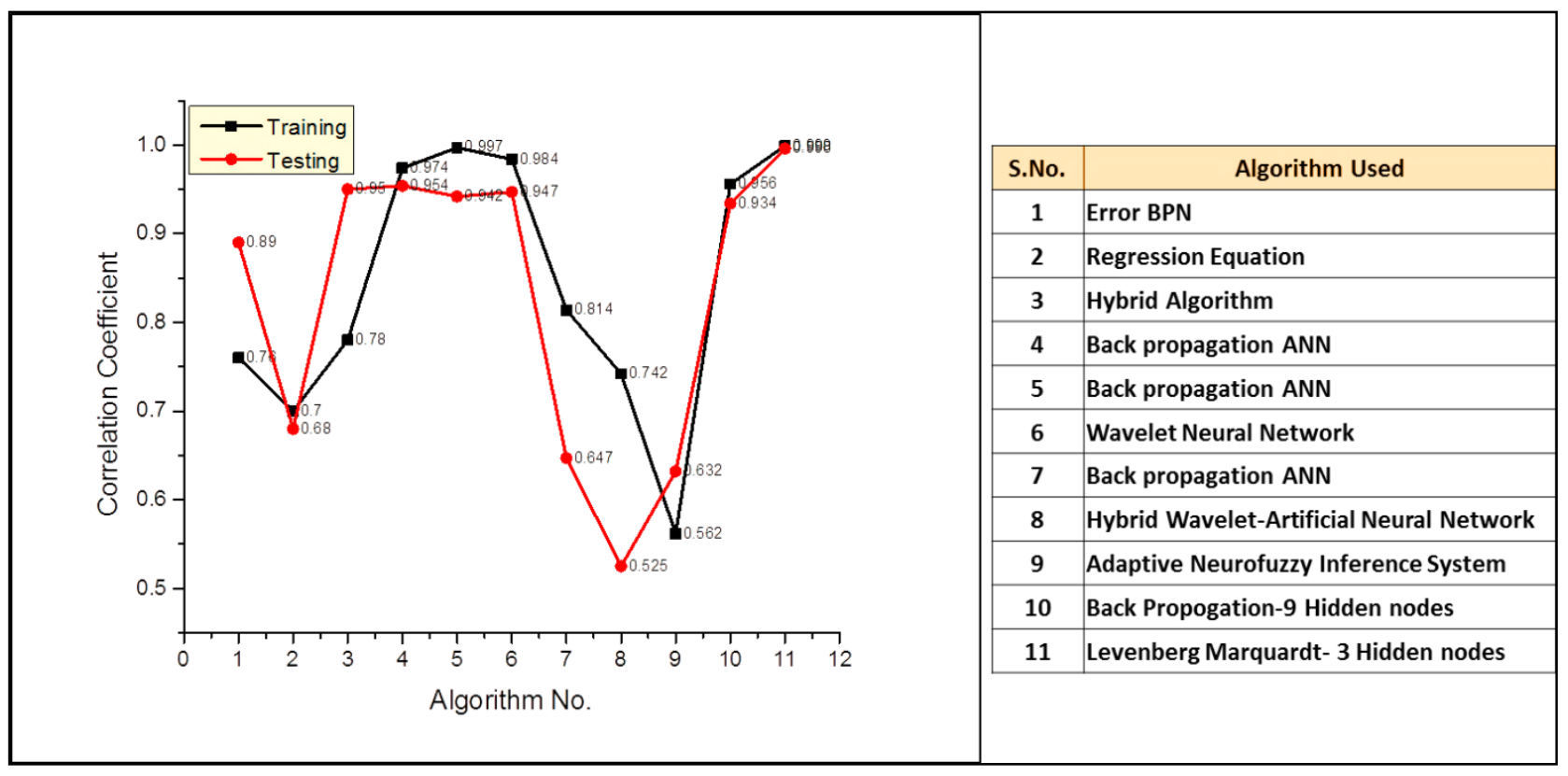

Figure 01 Comparison of various ANN algorithms used

For a better understanding of the above-mentioned facts, a graphical comparative analysis of various ANN algorithms was done. Figure 01 and Table 02 expressed that the best correlation coefficient for training and testing was $0.99 \& 0.96$ respectively which were found using the Backpropagation neural network with Levenberg Marquardt algorithm reported by Hashim et al.

Finally, after going through the literature, the comments of the researchers and working professionals on various platforms, the ANN is observed as a good tool for solving the chaotic time series like rainfall

\section{CONCLUSION}

Forecasting techniques using various algorithms such as MLP (Multi-Layer Perceptron), BPN (Backpropagation Network), ARIMA (Auto Regressive integrated moving average), MT (Model Tree), ANFIS (Artificial Neural Fuzzy Inference System), WNN (Wavelet Neural network) and SVR (Support Vector Regression) have been reported to be suitable for prediction. The absolute errors and the Root mean square errors (RMSE) values reported for prediction using neural network were significantly below when the same is compared for a few statistical and numerical methods.

Most of the researchers looked to be working on Backpropagation neural network with Levenberg Marquardt algorithm for prediction because of fairly good results found using it, as compared to other neural network techniques for forecasting.

The best correlation coefficient for training and testing was reported as $0.99 \& 0.96$ respectively, This accuracy was achieved using the Backpropagation neural network with Levenberg Marquardt algorithm reported Hashim et al. (2017)

There is always some scope for further development especially in forecasting using Machine Learning techniques. In view of current study, we can highlight the following scope for future research. We may go for Deep learning approach with Long Short Term Memory (LSTM) Neural Network \& Bidirectional Long Short Term (Bi-LSTM) Neural 
Network models for forecasting because both of models have proven to be very effective in prediction problem. Both of them preserve the temporal features in time series dataset .Swapna and Sudhakar (2018),Le et al.(2019). In LSTM, there are two more gates as compared to Gated Recurrent Unit (GRU), introduced as Forget and Output gates in addition to Update gate of GRU. So overall, LSTM introduced 2 Math operations having 2 new sets of Weights. Therefore, we may conclude that, we may go form LSTM model for prediction as it provides more Control-ability and hence, better Results .(website link accessed on 6.07.20.)

\section{REFERENCES}

[1]. Abdulkadir T.S., Salami A.W. and Kareem A.G. (2012). Artificial neural network of rainfall in Ilorin, Kwara State, Nigeria, USEP Research information in Civil Engineering, 9(1), pp. 108120, Available at www.useprice.webs.com.

[2]. Abdulkadir, T. S., Salami, A. W., Aremu, A. S., Ayanshola, A. M., Oyejobi, (2017). Assessment of Neural Networks Performance in Modeling Rainfall Amounts. Journal of Research in Forestry, Wildlife and Environment, Vol 9, Issue 1, Pp.12-22.

[3]. Adamowski J.; Sun, K. Development of a coupled wavelet transform and neural network method for flow forecasting of non-perennial rivers in semi-arid watersheds. J. Hydrol. 2010, 390, pp. 85-91.

[4]. Alhashimi, A.S.M. (2014). Prediction of Monthly Rainfall in Kirkuk Using Artificial Neural Network and Time Series Models, Journal of Engineering and Development, Vol.18, No.1, pp. 130-143.

[5]. Avik G. D., Deepanwita, G, Dasgupta, S, De, U. K.( 2010.), "Higher Order Markov Chain Models for Monsoon Rainfall Over West
Bengal, India”, Indian Journal of Radio and Space Physics, Vol. 39, Pp. 39 - 44.

[6]. Badaoui , H. E., A. Abdallaoui, I. Manssouri and H. Ousmana (2013). The prediction of moisture through the use of neural networks MLP type, IOSR Journal of Computer Engineering, Vol. 11, No. 06, pp.66-74.

[7]. Badrzadeh, H., Sarukkalige, R., Jayawardena, A.W., 2015. Hourly runoff forecasting for flood risk management: application of various computational intelligence models. J. Hydrol. 529 (3), 1633-1643.

[8]. Bowden, G.J., Dandy, G.C., Maier, H.R., (2005), Input determination for neural network models in water resources applications: Part1background and methodology. J.Hydrol.301, 75-92.

[9]. Box, G.E.P., Jenkins, G.M., (1976). Time Series Analysis: Forecasting and Control. Holden-Day, San Francisco, CA.

[10]. Bras, R.L., Rodriguez-Iturbe, I., (1994). Random Functions and Hydrology. Dover, New York.

[11]. Brockwell, P.J., Davis, R.A., (1987). Time Series: Theory and Methods. Springer, New York.

[12]. Chakraborty, K., Mehootra, K., Mohan, C.K., Ranka, S., (1992). Forecasting the behavior of multivariate series using neural networks. Neural Network. Vol. 5, pp. 961-970.

[13]. Chen, S. M., Y. M. Wang and I. Tsou (2013). Using an artificial neural network approach for modelling rainfall-runoff due to typhoon, Journal of Earth System Sciences, Vol. 122, No. 02, pp. 399-405.

[14]. Dahamsheh, A. and H. Aksoy (2009). Artificial neural network models for forecasting intermittent monthly precipitation in arid regions, Meteorological Applications, Vol. 16, pp. 325-337.

[15]. Dawson, C.W., Wilby, R.L.,(2001). Hydrological modeling using artificial neural 
networks. Prog. Phys. Geography 25 (1), pp. 80-108.

[16]. F.R. Hashim, N.G.N. Daud, K.A. Ahmed, J. Adnan, and Z. I. Rizman (2017), Prediction of rainfall based on weather parameter using Artificial Neural Network, Journal of Fundamental and Applied Sciences, vol 9, pp. 493-502

[17]. Farajzadeh, J., A. F. Fard and S. Lotfi (2014). Modeling of monthly rainfall and runoff of Urmia lake basin using feed-forward neural network and time series analysis model. Water Resources and Industry, Vol. 07-08, pp. 38-48.

[18]. Fausett L., Fundamentals of Neural Network: Architecture, Algorithms, and Applications, Prentice hall, International Edition, 1994.

[19]. French, M.N., Krajewski, W.F., Cuykendall, R.R., (1992). Rainfall forecasting in space and time using a neural network. Journal of Hydrology, Vol. 137, pp. 1-31.

[20]. Garcia, E.G.O., S.S. Sanz and C.C. Mateo (2014). Accurate precipitation prediction with support vector classifiers: A study including novel predictive variables and observational data, Atmospheric Research, Vol. 139, pp. 128-136.

[21]. Guhathakurta, P., Rajeevan, M.and Thapliyal, V. (1999). Long-range forecasting Indian summer monsoon rainfall by a hybrid principal component neural network Model, journal of Meteorological Atmospheric Physics, Vol. 71, pp. 255-266.

[22]. Gunn, S.R., 1998. Support vector machines for classification and regression., Image, Speech and Intelligent Systems Technology Rep. University of Southampton, U.K.

[23]. Hagan MT, Menhaj MB (1994) Training feed forward networks with Marquardt algorithm. IEEE Trans Neural Netw 5:989-993

[24]. Haykin, S. 1999. Neural networks, New York, NY, USA, MacMillan Publishing Company.
[25]. Hong, W. (2008). Rainfall forecasting by technological machine learning models, Applied Mathematics and Computation, Vol. 200, pp. 41-57.

[26]. http://dx.doi.org/10.1061/(ASCE)CP.1943-

5487.0000457.(accessed on 06.07.20)

[27]. http://dx.doi.org/10.1061/(ASCE)CP.1943-

5487.0000457.(accessed on 06.07.20) https://medium.com/@saurabh.rathor092/simpl e-rnn-vs-gru-vs-lstm-difference-lies-in-moreflexible control-5f33e07b1e57 (accessed on 06.07.20)

[28]. Hung, N. Q., M. S. Babel, S. Weesakul, and N. K. Tripathi (2009). An artificial neural network for rainfall forecasting in Bangkok, Thailand, Hydrology Earth System Science, Vol. 13, pp. 1413-1425.

[29]. Hung, N. Q., M. S. Babel, S. Weesakul, and N. K. Tripathi (2009). An artificial neural network for rainfall forecasting in Bangkok, Thailand, Hydrolology Earth System Science, Vol. 13, pp. 1413-1425.

[30]. Jeongwoo Lee, Chul-Gyum Kim, Jeong Eun Lee, Nam Won Kim and Hyeonjun Kim, Application of Artificial Neural Networks to Rainfall Forecasting in the Geum River Basin, Korea, Water 2018, 10, 1448

[31]. K.S. Kasiviswanathan, R. Cibin, K.P. Sudheer, I. Chaubey (2013), Constructing prediction interval for artificial neural network rainfall runoff models based on ensemble simulations, Journal of Hydrology 499 pp. 275-288.

[32]. Karim, S. (2009). Rainfall-runoff prediction based on artificial neural network (A case study: Jarahi watershed), American-Eurasian J. Agric. \& Environ. Sci., 5 (6), pp. 856-865.

[33]. Karlsson, M., Yakowitz, S., (1987a). Nearestneighbour methods for nonparametric rainfallrunoff forecasting. Water Resources Research, Vol. 23, 1300-1308. 
[34]. Karlsson, M., Yakowitz, S., (1987b). Rainfallrunoff forecasting methods, old and new. Stochastic Hydrology and Hydraulic, Vol. 1, pp. 303-318.

[35]. Khalili, N., S. R. Khodashenas, K. Davary and F. Karimaldini (2011). Daily rainfall forecasting for mashhad synoptic station using artificial neural networks, International Conference on Environmental and Computer Science, pp. 118123, Singapore.

[36]. Kompare, B., Steinman, F., Cerar, U. \& Dzeroski, S. (1997). Prediction of rainfall runoff from catchment by intelligent data analysis with machine learning tools within the artificial intelligence tools. Acta Hydrotechnica (in Slovene) 16/17, pp. 79-94.

[37]. Kristen, B.D. and Lee, W.L. (2003). Artificial neural networks for the management researcher: The state of the art, Department of Organizational Leadership and Strategy, Marriott School of Management Brigham Young University Provo, UT 84602.

[38]. Kumar, D.N., M.J. Reddy and R. Maity (2007). Regional Rainfall Forecasting using Large Scale Climate Teleconnections and Artificial Intelligence Techniques, Journal of Intelligent Systems, Vol. 16, No 4, pp. 307-322.

[39]. Lin, C. T., Lee, C. S. G., 1995, "Neural fuzzy systems", Prentice Hall P T R 797, New Jersey.

[40]. Luk, K. C, J. E. Ball and A. Sharma (2001). An application of artificial neural networks for rainfall forecasting, Mathematical and Computer Modelling, Vol. 33, pp. 683-693.

[41]. Luk, K. C, J. E. Ball and A. Sharma (2001). An application of artificial neural networks for rainfall forecasting, Mathematical and Computer Modelling, Vol. 33, pp. 683-693.

[42]. M.Swapna, N.Sudhakar(2018), A HYBRID MODEL FOR RAINFALL PREDICTION USING BOTH PARAMETRIZED AND TIME SERIES MODELS, International Journal of Pure and Applied Mathematics, vol 119, pp. 15491556.

[43]. Maeda, N., S. Kobayashi, K. Izumi, S. Kouno and M. Amenomori (2001). Prediction of precipitation by a neural network method, Journal of Natural Disaster Science, Vol. 23, No. 01, pp. 23-33.

[44]. Mandal , T. and V. Jothiprakash (2012). Shortterm rainfall prediction using ANN and MT techniques, ISH Journal of Hydraulic Engineering, Vol. 18, No. 01, pp. 28-37.

[45]. Mar K. W. and T. T. Naing (2008) Optimum neural network architecture for precipitation prediction of Myanmar, International Journal of Environmental, Chemical, Ecological, Geological and Geophysical Engineering, Vol. 02, No. 12, pp. 154-158.

[46]. Mislan , Haviluddin, S. Hardwinarto, Sumaryono and M. Aipassa (2015). Rainfall monthly prediction based on artificial neural network: A Case Study in Tenggarong Station, east Kalimantan Indonesia, Procedia Computer Science, Vol. 59, pp. 142 - 151.

[47]. Mislan, Haviluddin, Sigit Hardwinarto, Sumaryono, Marlon Aipassa, Rainfall Monthly Prediction Based on Artificial Neural Network: A Case Study in Tenggarong Station, East Kalimantan Indonesia, Procedia Computer Science 59 ( 2015 ) pp. 142 - 151.

[48]. Moustris , K. P., I. K. Larissi, P. T. Nastos and A. G. Paliatsos (2011). Precipitation forecast using artificial neural networks in specific regions of Greece, Water Resource Management, Vol. 25, No. 08, pp. 1979-1993.

[49]. Nanda, T., B. Sahoo, H. Beria and C. Chatterjee (2016). A wavelet-based non-linear autoregressive with exogenous inputs (WNARX) dynamic neural network model for real time flood forecasting using satellite-based rainfall products. Journal of Hydrology, Vol.539, pp. 57-73. 
[50]. Narvekar, M. and P. Fargose (2015). Daily Weather Forecasting using Artificial Neural Network, International Journal of Computer Applications, Vol. 121, No. 22, pp. 09-13.

[51]. Nasseri, M., K. Asghari and M. J. Abedini (2008). Optimized scenario for rainfall forecasting using genetic algorithm coupled with artificial neural network, Expert Systems with Applications, Vol. 35, No. 03, pp. 14151421.

[52]. Nayak, R.D.; Mahapatra, A.; Mishra, P (2013), A survey on rainfall prediction using artificial neural network. Int. J. Comput. Appl., 72, pp. 32-40.

[53]. Obeysekera, J.T.B., Tabios III, G.Q., Salas, J.D., (1987). On parameter estimation of temporal rainfall models. Water Resources Research, Vol. 23, pp.1837 -1850.

[54]. Olaiya, F. and A. B. Adeyemo (2012). Application of data mining techniques in weather prediction and climate change studies, International Journal of Information Engineering and Electronic Business, Vol. 01, pp. 51-59.

[55]. P. Guhathakurta, Long lead monsoon rainfall prediction for meteorological sub-divisions of India using deterministic artificial neural network model, Meteorology and Atmospheric Physics 101, 93-108 (2008)

[56]. Partal, T., H. K. Cigizoglu and E. Kahya (2015). Daily precipitation predictions using three different wavelet neural network algorithms by meteorological data, Stochastic Environmental Research and Risk Assessment, Vol. 29, pp. 1317-1329.

[57]. Philip, N.S. and K.B. Joseph (2003). A Neural Network tool for analysing trends in rainfall, Computational Geoscience, Vol. 29, pp. 215223.

[58]. Ping-Cheng Hsieh, Wei-An Tong \& YungChieh Wang (2019),A hybrid approach of artificial neural network and multiple regression to forecast typhoon rainfall and groundwater-level change, Hydrological Sciences Journal.

[59]. Quinlan, J. R. (1992) Learning with continuous classes. In: Proc. AI'92 (Fifth Australian Joint Conf. on Artificial Intelligence) (ed. by A. Adams \& L. Sterling), 343-348. World Scientific, Singapore.

[60]. Rajashree Acharya, Jayanti Pal, Debanjana Das and Sutapa Chaudhuri (2018), Long Range Forecast of Indian Summer Monsoon Rainfall using Artificial Neural Network Model, Meteorological Applications pp. 347-361.

[61]. S.Renuga Devi P. Arulmozhivarman C. Venkatesh Pranay Agarwal (2016), Performance Comparison of Artificial Neural Network Models for Daily Rainfall Prediction, International Journal of Automation and Computing, DOI: 10.1007/s11633-016-0986-2 (2016)

[62]. Sahai, A.K., M.K. Soman and V. Satyan (2000). All India summer monsoon rainfall prediction using an artificial neural network, Climate Dynamics, Vol. 16, pp. 291-302.

[63]. Sehgal, V., Sahay, R.R., Chatterjee, C., 2014a. Effect of utilization of discrete wavelet components on flood forecasting performance of wavelet based ANFIS models. Water Resour. Manage. 28, 1733-1749.

[64]. Sehgal, V., Tiwari, M.K., Chatterjee, C., 2014b. Wavelet bootstrap multiple linear regression based hybrid modeling for daily river discharge forecasting. Water Resour. Manage. 28 (10), 2793-2811.

[65]. Shoaib, M., Shamseldin, A.Y., Melville, B.W., Khan, M.M., 2014. Hybrid wavelet neuro-fuzzy approach for rainfall-runoff modeling. J. Comput. Civ. Eng. 1-16.

[66]. Shoaib, M., Shamseldin, A.Y., Melville, B.W., Khan, M.M., 2014. Hybrid wavelet neuro-fuzzy 
approach for rainfall-runoff modeling. J. Comput. Civ. Eng. 1-16.

[67]. Solgi, A., V. Nourani and A. Pourhaghi (2014). Forecasting Daily Precipitation Using Hybrid Model of Wavelet-Artificial Neural Network and Comparison with Adaptive Neuro fuzzy Inference System (Case Study: Verayneh Station, Nahavand), Advances in Civil Engineering, Vol. 2014, pp.1-12.

[68]. Solomatine, Dimitri P, Khada N.D (2003). Model Trees as an Alternative to Neural Networks in Rainfall-Runoffff Modelling, Hydrological Sciences Journal, Vol. 48, Issue 3, pp. 399-411.

[72]. /SNNS/

[73]. Sudheer, K.P., Nayak, P.C., Ramasastri, K.S., 2003. Improving peak flow estimates in artificial neural network river flow models. Hydrol. Process. 17, 677-686.

[74]. Tiwari, M.K., Chatterjee, C., 2011. A new Wavelet-Bootstrap-ANN hybrid model for daily discharge forecasting. J. Hydroinf. 13 (3), 500-519.

[75]. Toth, E., A. Brath, and A. Montanari (2000). Comparison of short-term rainfall prediction models for real-time flood forecasting, Journal of Hydrology, Vol. 239, pp.132-147.

[76]. Vamsidhar, E., K.V.S.R.P. Varma, P. Sankara Rao and R. Satapati (2010). Prediction of rainfall using Backpropagation Neural Network Model, International Journal of Computer Science and Engineering, Vol. 2, No. 4, pp. 1119-1121.

[77]. Venkata Ramana, R., B. Krishna, S.R. Kumar and N.G. Pandey (2013). Monthly rainfall prediction using wavelet neural network analysis, Water Resources Management, Vol. 27, No. 10, pp. 3697-3711.
[69]. Somvanshi, V.K., Pandey, O.P., Agrawal, P.K. Kalanker, N.V., Prakash, M.R. and Ramesh, C. (2006). Modelling and prediction of rainfall using artificial neural network and ARIMA techniques, J. Ind. Geophys. Union, 10(2), pp. 141-151.

[70]. Srikalra, N. and C. Tanprasert (2006). Rainfall Prediction for Chao Phraya River using Neural Networks with Online Data Collection, Proc. of the 2nd IMT-GT Regional Conference on Mathematics, Statistics and Applications, Penang, pp. 1-8, Malaysia.

[71]. Stuttgart Neural Network Simulator (SNNS) at http://www-ra.informatik.unituebingen.de

[78]. Witten, I. H. \& Frank, E. (2000) Data Mining: Practical Machine Learning Tools and Techniques with Java Implementations. Morgan Kaufmann Publishers, San Francisco, USA.

[79]. Wu, C.L. and K.W. Chau (2013). Prediction of rainfall time series using modular soft computing methods, Engineering Applications of Artificial Intelligence, Vol. 26, pp. 997-1007.

[80]. Wu, C.L., Chau, K.W., Li, Y.S.,(2008). River stage prediction based on a distributed support vector regression. J. Hydrol. 358, pp.

\section{Cite this article as :}

Nisha Thakur, Sanjeev Karmakar, Sunita Soni, "Rainfall Forecasting Using Various Artificial Neural Network Techniques - A Review", International Journal of Scientific Research in Computer Science, Engineering and Information Technology (IJSRCSEIT), ISSN : 2456-3307, Volume 7, Issue 3, pp.506-526, May-June-2021. Available at doi $\quad$ : https://doi.org/10.32628/CSEIT2173159 Journal URL : https://ijsrcseit.com/CSEIT2173159 
Table 01 Various ANN techniques reported by various authors

\begin{tabular}{|c|c|c|c|c|c|c|c|c|c|}
\hline \multicolumn{10}{|c|}{ Summary of Literature } \\
\hline \multirow{3}{*}{$\begin{array}{l}\text { S. } \\
\text { No. }\end{array}$} & \multirow{3}{*}{ Author } & \multirow{3}{*}{ Technology used } & \multirow{3}{*}{ Architecture } & \multicolumn{6}{|c|}{ Findings } \\
\hline & & & & \multicolumn{3}{|c|}{ Training } & \multicolumn{3}{|c|}{ Testing } \\
\hline & & & & RMSE & PP & CC & RMSE & $\mathrm{PP}$ & $\mathrm{CC}$ \\
\hline 1 & Basu and Andharia(1987) & Error BPN & $\longrightarrow$ & SM-50.9 & 0.42 & 0.76 & 41.3 & 0.24 & 0.89 \\
\hline 2 & Shukla and Mooley (1992) & Regression Equation & $\longrightarrow$ & BA-56.5 & 0.52 & 0.7 & 66.7 & 0.61 & 0.68 \\
\hline \multirow{3}{*}{3} & \multirow{3}{*}{ Sahai et al.(2000) } & \multirow{3}{*}{ Back propagation ANN } & \multirow{3}{*}{$25-2-4-1$} & NC-50.6 & 0.41 & 0.77 & 33.6 & 0.16 & 0.94 \\
\hline & & & & NC-61.2 & 0.56 & 0.62 & 41.7 & 0.25 & 0.87 \\
\hline & & & & NC-49.0 & 0.39 & 0.78 & 26.7 & 0.1 & 0.95 \\
\hline \multirow{7}{*}{4} & \multirow{7}{*}{ Toth et al.(2000) } & \multirow{7}{*}{$\begin{array}{l}\text { Auto-Regressive Moving } \\
\text { Average (ARMA), ANN } \\
\text { and K- Nearest } \\
\text { Neighbourhood (K-NN) }\end{array}$} & \multirow{2}{*}{ Time-series analysis technique } & \multicolumn{6}{|c|}{$\begin{array}{l}\text { Mean correlation coefficients of predictions } \\
\text { for different rainfall ranges }\end{array}$} \\
\hline & & & & \multicolumn{2}{|c|}{$\begin{array}{l}\text { Low rainfall } \\
(, 0.1 \mathrm{~mm})\end{array}$} & \multicolumn{2}{|c|}{$\begin{array}{l}\text { Medium rainfall } \\
(0.1-1 \mathrm{~mm})\end{array}$} & \multicolumn{2}{|c|}{$\begin{array}{l}\text { High rainfall } \\
(.1 \mathrm{~mm})\end{array}$} \\
\hline & & & ANN split-sample- $\mathrm{NI}^{\wedge} 18, \mathrm{NH}^{\wedge} 2$ & \multicolumn{2}{|c|}{0.203} & \multicolumn{2}{|c|}{0.257} & \multicolumn{2}{|c|}{0.178} \\
\hline & & & ARMA split-sample- Almost all equivalent & \multicolumn{2}{|c|}{0.216} & \multicolumn{2}{|c|}{0.18} & \multicolumn{2}{|c|}{20.001} \\
\hline & & & Nearest Neighbours- $K=70, d={ }^{\wedge} 2$ & \multicolumn{2}{|c|}{0.268} & \multicolumn{2}{|c|}{0.121} & \multicolumn{2}{|c|}{0.119} \\
\hline & & & ANN adaptive- $\mathrm{NI}=3, \mathrm{NH}={ }^{\wedge} 3$ & \multicolumn{2}{|c|}{0.075} & \multicolumn{2}{|c|}{0.115} & \multicolumn{2}{|c|}{0.028} \\
\hline & & & ARMA adaptive $=p^{\wedge}=1, q={ }^{\wedge} 0$ & 0. & & \multicolumn{2}{|c|}{0.205} & \multicolumn{2}{|c|}{0.008} \\
\hline & & $\begin{array}{l}\text { Multi- Layer Feed } \\
\text { Forward Neural Network }\end{array}$ & (ANN Techniques) & Training (NMSE) & $\begin{array}{l}\text { Monitoring } \\
\text { (NMSE) }\end{array}$ & $\begin{array}{l}\text { Validation } \\
\text { (NMSE) }\end{array}$ & $\begin{array}{l}\text { Stopping } \\
\text { epochs }\end{array}$ & $\begin{array}{r}\text { Traini } \\
\text { ep }\end{array}$ & $\begin{array}{l}\text { at } 100 \\
\text { ASE) }\end{array}$ \\
\hline 5 & Luk et al.(2001) & $\begin{array}{l}\text { recurrent neural } \\
\text { reli }\end{array}$ & MLFN Lag-1:- 16-24-16 & 0.5 & 0.68 & 0.64 & 200 & & \\
\hline & & Neural Network (TDNN) & Ellman :- 16-4-16 & 0.49 & 0.67 & 0.64 & 300 & & \\
\hline & & & TDNN Lag 3 - :- 32-16-16 & 0.5 & 0.69 & 0.64 & 100 & & \\
\hline
\end{tabular}




\begin{tabular}{|c|c|c|c|c|c|c|c|c|c|c|c|c|}
\hline \multirow{9}{*}{6} & \multirow{9}{*}{$\begin{array}{c}\text { Solomatine, Dimitri P, Khada } \\
\text { N.D.,(2003) }\end{array}$} & \multirow{9}{*}{$\begin{array}{l}\text { Back Propogation ANN } \\
\& \text { Model Tree(MT) }\end{array}$} & \multicolumn{4}{|c|}{ ANN/MT } & $\operatorname{RMSE}\left(m^{3} \mathrm{~s}^{-1}\right)$ & NRMSE & COE & RMSE $\left(m^{3} s^{-1}\right)$ & NRMSE & COE \\
\hline & & & $\begin{array}{c}\text { Input } \\
\text { variables }\end{array}$ & $\begin{array}{l}\text { Output } \\
\text { variable }\end{array}$ & $\begin{array}{c}\text { Hidden } \\
\text { nodes }\end{array}$ & $\begin{array}{l}\text { Linear } \\
\text { models }\end{array}$ & \multicolumn{3}{|c|}{ ANN } & \multicolumn{3}{|c|}{ ANN } \\
\hline & & & $\begin{array}{l}\text { REt, REt-1, } \\
\text { REt-2, REt- } \\
\text { 3, REt-4, } \\
\text { REt-5, Qt, } \\
\text { Qt-1, Qt-2 }\end{array}$ & $Q_{t+1}$ & 6 & 3 & 5.175 & 0.106 & 0.989 & & - & \\
\hline & & & $\begin{array}{l}\text { REt, REt-1, } \\
\text { REt-2, REt- } \\
3 \text {, Qt, at-1 }\end{array}$ & $Q_{t+3}$ & 5 & 3 & 11.353 & 0.234 & 0.945 & & & \\
\hline & & & REt, Qt & $Q t+6$ & 3 & 9 & 19.402 & 0.399 & 0.84 & 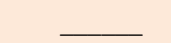 & 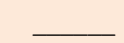 & 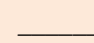 \\
\hline & & & $\begin{array}{c}\text { Input } \\
\text { variables }\end{array}$ & $\begin{array}{l}\text { Output } \\
\text { variable }\end{array}$ & $\begin{array}{l}\text { Hidden } \\
\text { nodes }\end{array}$ & & \multicolumn{3}{|c|}{ MT } & \multicolumn{3}{|c|}{ MT } \\
\hline & & & $\begin{array}{l}\text { REt, REt-1, } \\
\text { REt-2, REt- } \\
\text { 3, REt-4, } \\
\text { REt-5, Qt, } \\
\text { Qt-1, Qt-2 }\end{array}$ & $Q_{t+1}$ & 6 & & 3.612 & 0.074 & 0.994 & & 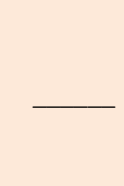 & \\
\hline & & & $\begin{array}{l}\text { REt, REt-1, } \\
\text { REt-2, REt- } \\
\text { 3, Qt, Qt-1 }\end{array}$ & $Q_{t+3}$ & 5 & & 12.548 & 0.258 & 0.933 & 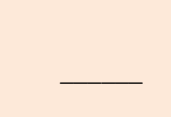 & 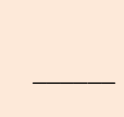 & \\
\hline & & & REt, Qt & $\mathrm{Q} t+6$ & 3 & & 21.547 & 0.443 & 0.803 & {[} & {[} & 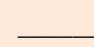 \\
\hline 7 & Philip and Joseph (2003) & Adaptive Basis Function & \multicolumn{4}{|c|}{ 12:07:01 } & \multicolumn{3}{|c|}{0.954} & \multicolumn{3}{|c|}{0.948} \\
\hline
\end{tabular}




\begin{tabular}{|c|c|c|c|c|c|c|c|c|c|}
\hline & & $\begin{array}{l}\text { Neural Network } \\
\text { (ABFNN), }\end{array}$ & & & & & & & \\
\hline \multirow{3}{*}{8} & \multirow{3}{*}{ Srikalra and Tanprasert (2006) } & \multirow{3}{*}{ Back propagation ANN } & \multirow{3}{*}{ 5:10:01 } & TYPE-I & \multicolumn{2}{|c|}{$97.67 \%$} & TYPE-I & \multicolumn{2}{|c|}{$94.99 \%$} \\
\hline & & & & TYPE-II & \multicolumn{2}{|c|}{$97.16 \%$} & TYPE-II & \multicolumn{2}{|c|}{$95.88 \%$} \\
\hline & & & & Average & \multicolumn{2}{|c|}{$97.42 \%$} & Average & \multicolumn{2}{|c|}{$95.44 \%$} \\
\hline \multirow{5}{*}{9} & \multirow{5}{*}{ Kumar et al.(2007) } & \multirow{5}{*}{$\begin{array}{c}\text { Back propagation ANNs } \\
\text { with steepest gradient } \\
\text { descent technique }\end{array}$} & June $7,7,7,1$ & ${ }^{-}$ & 工 & 0.994 & {[} & 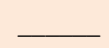 & 0.8349 \\
\hline & & & July $7,8,9,1$ & $\ldots$ & 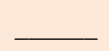 & 0.999 & $\ldots$ & 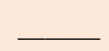 & 0.8002 \\
\hline & & & August $7,10,1$ & 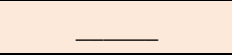 & $\underline{-}$ & 0.997 & $\underline{-}$ & 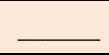 & 0.8102 \\
\hline & & & September $7,8,1$ & {[} & 工 & 1 & ${ }^{-}$ & 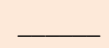 & 0.5775 \\
\hline & & & JJAS 7,8,1 & 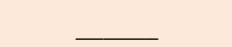 & 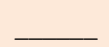 & 0.998 & 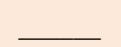 & 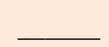 & 0.8951 \\
\hline \multirow{3}{*}{10} & \multirow{3}{*}{ Mar et al.(2008) } & \multirow{3}{*}{$\begin{array}{l}\text { Backpropagation } \\
\text { method (BPNN) }\end{array}$} & \multirow{3}{*}{$(3-10-1)$} & \multicolumn{3}{|c|}{$\begin{array}{c}\text { RESULTS OF YANGON USING } 3 \text { INPUT NODES NN } \\
\text { MODEL }\end{array}$} & - & & 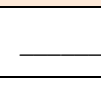 \\
\hline & & & & $\begin{array}{l}\text { No. of Hidden } \\
\text { Nodes }\end{array}$ & RMSE & MAPE & _ & 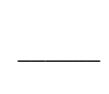 & 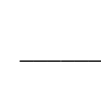 \\
\hline & & & & 10 & 9.881 & 1.649 & {[} & 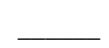 & 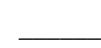 \\
\hline \multirow[b]{2}{*}{11} & \multirow[b]{2}{*}{ P. Guhathakurta(2006) } & \multirow[b]{2}{*}{$\begin{array}{l}\text { Back-propagation } \\
\text { learning algorithm }\end{array}$} & \multirow[b]{2}{*}{ one input layer, one hidden layer and one output layer } & $\begin{array}{l}\text { All India:- } \\
16.6 \mathrm{~mm}\end{array}$ & $\longrightarrow$ & 0.6 & - & & 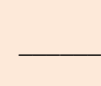 \\
\hline & & & & $\begin{array}{l}\text { Sub-division area } \\
\text { weighted:-11 } \mathrm{mm}\end{array}$ & $\longrightarrow$ & 0.9 & - & & - \\
\hline
\end{tabular}




\begin{tabular}{|c|c|c|c|c|c|c|c|c|c|}
\hline 12 & Vamsidhar et al.(2010) & $\begin{array}{l}\text { Back Propagation Neural } \\
\text { Network Model }\end{array}$ & 3:07:01 & 0.21027 & & & 5.82425 & & \\
\hline \multirow{9}{*}{13} & \multirow{9}{*}{ Wu and Chau(2013) } & \multirow{9}{*}{$\begin{array}{l}\text { MA and SSA techniques } \\
\text { are used in combination } \\
\text { with ANN and Support } \\
\text { Vectors Regression (SVR) } \\
\text { models. }\end{array}$} & STATIONS & RMSE & PI & C.E & RMSE & PI & C.E \\
\hline & & & \multirow{2}{*}{ India-12-5-1 } & MA-69.2 & 0.99 & 0.99 & & & \\
\hline & & & & $\begin{array}{c}M A+S S A- \\
104.1\end{array}$ & 0.97 & 0.99 & & $\longrightarrow$ & \\
\hline & & & \multirow{2}{*}{ Zhongxian-13-6-1 } & MA-35.6 & 0.78 & 0.77 & & & \\
\hline & & & & $M A+S S A-44.9$ & 0.65 & 0.64 & & & \\
\hline & & & \multirow{2}{*}{ Wuxi-7-6-1 } & MA-5.3 & 0.81 & 0.82 & & & \\
\hline & & & & $\mathrm{MA}+\mathrm{SSA}-5.8$ & 0.77 & 0.79 & & & \\
\hline & & & \multirow[b]{2}{*}{ Zhenwan- 3-4-1 } & MA-4.4 & 0.81 & 0.81 & & & \\
\hline & & & & $M A+S S A-5.6$ & 0.8 & 0.69 & & & \\
\hline \multirow[b]{2}{*}{14} & \multirow[b]{2}{*}{ Venkata Ramana et al.(2013) } & \multirow[b]{2}{*}{$\begin{array}{l}\text { Hybrid Model combining } \\
\text { wavelet techniques and } \\
\text { Back propagation ANN }\end{array}$} & & RMSE & $\mathrm{R}$ & $\operatorname{COE}(\%)$ & RMSE & $\mathrm{R}$ & $\operatorname{COE}(\%)$ \\
\hline & & & 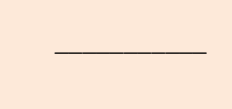 & $\begin{array}{l}\text { WNN Model:- } \\
\quad 35.12\end{array}$ & 0.992 & 98.48 & $\begin{array}{l}\text { WNN Model:- } \\
\quad 63.01\end{array}$ & 0.974 & 94.78 \\
\hline
\end{tabular}




\begin{tabular}{|c|c|c|c|c|c|c|c|c|c|}
\hline & & & & $\begin{array}{l}\text { ANN Model:- } \\
123.23\end{array}$ & 0.902 & 81.49 & $\begin{array}{l}\text { ANN Model:- } \\
163.79\end{array}$ & 0.807 & 64.73 \\
\hline 15 & Garcia et al(2104) & $\begin{array}{l}\text { Support Vector } \\
\text { Machines (SVM) with } \\
\text { decision trees, Knearest } \\
\text { neighbour, multilayer } \\
\text { perceptron. }\end{array}$ & 4- 35- 1 & \multicolumn{3}{|c|}{4.984} & \multicolumn{3}{|c|}{3.684} \\
\hline \multirow{3}{*}{16} & \multirow{3}{*}{ Alhashimi(2104) } & \multirow{3}{*}{$\begin{array}{l}\text { ARIMA (Auto } \\
\text { Regressiveintegrated } \\
\text { moving average), ANN } \\
\text { (Ariticial neural network) } \\
\text { and MLR(Multi linear } \\
\text { regression). }\end{array}$} & $\operatorname{ANN}(4,8,1)$ & - & - & - & 27.278 & - & 0.91 \\
\hline & & & ARIMA (1 00 o) & - & - & - & 38.12 & - & 0.85 \\
\hline & & & MLR & - & - & - & 38.543 & - & 0.823 \\
\hline & \multirow[b]{3}{*}{ Solgi et al.(2014) } & \multirow[b]{3}{*}{$\begin{array}{l}\text { WANN Model, ANFIS } \\
\text { Model }\end{array}$} & \multirow[b]{3}{*}{ processing elements $=50$, hidden layer $=1$} & RMSE & $\mathrm{R}^{2}$ & $\mathrm{CE}$ & RMSE & $\mathrm{R}^{2}$ & $\mathrm{CE}$ \\
\hline & & & & $\begin{array}{l}\text { WANN Model:- } \\
0.021\end{array}$ & 0.903 & 0.743 & $\begin{array}{l}\text { WANN Model:- } \\
0.028\end{array}$ & 0.774 & 0.525 \\
\hline 17 & & & & $\begin{array}{c}\text { ANFIS Model:- } \\
\quad 0.027\end{array}$ & 0.613 & 0.562 & $\begin{array}{l}\text { ANFIS Model:- } \\
0.033\end{array}$ & 0.599 & 0.632 \\
\hline \multirow{7}{*}{18} & \multirow{7}{*}{ Farajzadeh et al. (2014) } & \multirow{7}{*}{$\begin{array}{l}\text { Feed-forwardNN and } \\
\text { ARIMA }\end{array}$} & \multirow{4}{*}{$(2,0,0)(4,1,2)^{12}$} & \multicolumn{3}{|c|}{ Error measures for monthly } & & & \\
\hline & & & & $\mathrm{R}$ & $\begin{array}{l}\text { RMSE } \\
(\mathrm{mm})\end{array}$ & $\begin{array}{l}\text { MAE } \\
(\mathrm{mm})\end{array}$ & & & \\
\hline & & & & 0.663 & 21.07 & 14.03 & & & \\
\hline & & & & 0.654 & 21.4 & 14.64 & & & \\
\hline & & & \multirow{3}{*}{$(2,1,2)(4,0,0)^{12}$} & \multicolumn{3}{|c|}{ Error measures for monthly } & & & \\
\hline & & & & $\mathrm{R}$ & $\begin{array}{l}\text { RMSE } \\
(\mathrm{mm})\end{array}$ & $\begin{array}{l}\text { MAE } \\
(\mathrm{mm})\end{array}$ & & - & \\
\hline & & & & 0.465 & 8.4 & 4.35 & & & \\
\hline
\end{tabular}




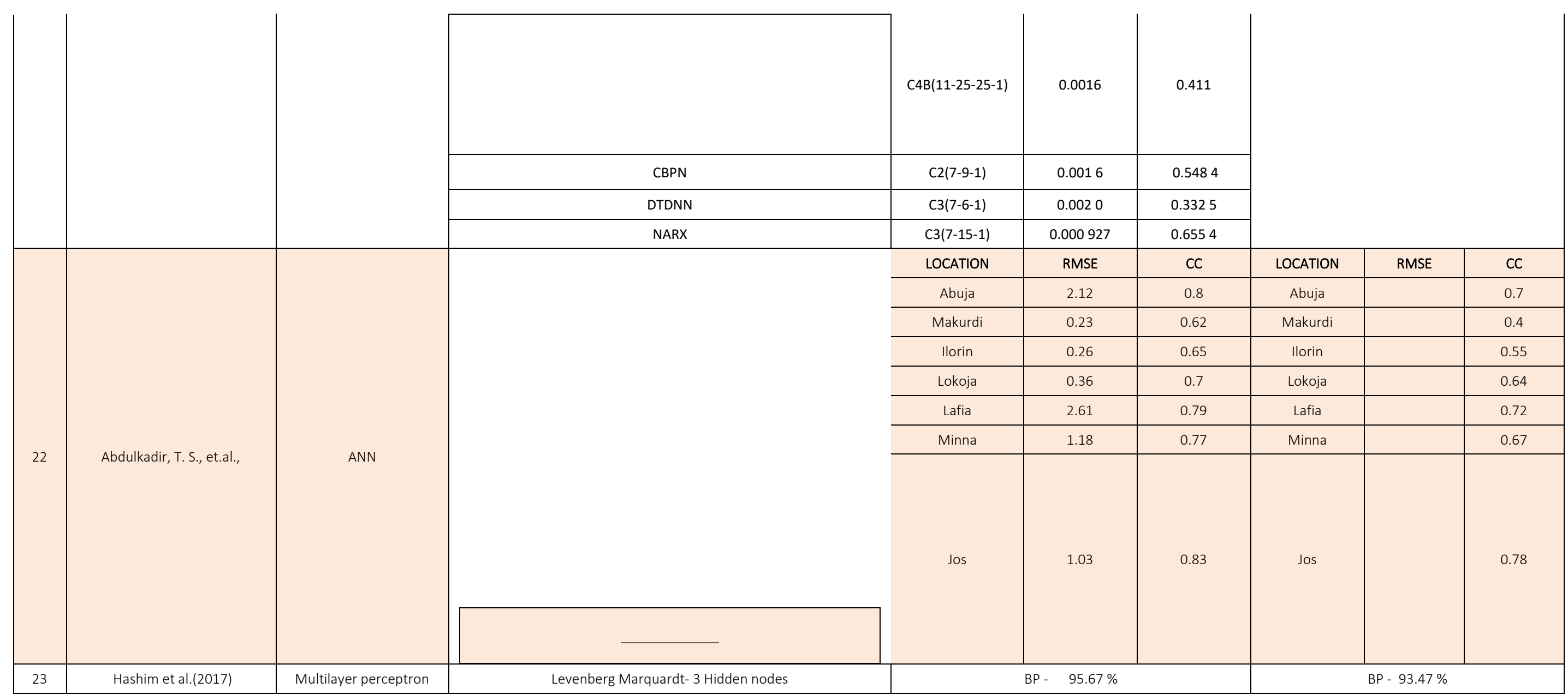




\begin{tabular}{|c|c|c|c|c|c|}
\hline \multicolumn{3}{|c|}{ LM - $99.9 \%$} & \multicolumn{3}{|c|}{ LM - $99.6 \%$} \\
\hline \multicolumn{3}{|c|}{ First stage forecast } & \multicolumn{3}{|c|}{$\begin{array}{l}\text { Second stage forecast of seasonal rainfall of } \\
\text { Indian summer monsoon }\end{array}$} \\
\hline MAE & PE & RMSE & MAE & PE & RMSE \\
\hline ANN:-0.15 & 0.3 & 0.22 & ANN:-0.15 & 0.28 & 0.18 \\
\hline MNLR:- 0.28 & 0.48 & 0.32 & MNLR:- 0.19 & 0.33 & 0.24 \\
\hline
\end{tabular}

